\title{
A avaliação transdisciplinar e poder: levantando algumas questões
}

\author{
Luiz Carlos de Oliveira Cecílio ${ }^{1}$
}

\begin{abstract}
$\mathrm{O}$ indivíduo que avalia o trabalho de alguém detém autoridade. $\mathrm{O}$ controle através da avaliação tem sua eficácia máxima quando os indivíduos avaliados acreditam que as avaliações são importantes, centrais para seu trabalho e passíveis de serem influenciadas por seus próprios esforços. Quando se acreditar que as avaliações têm base sólida, os indivíduos serão mais controlados pelo processo de avaliação.

(Richard Hall, Organizações, estruturas e processos)
\end{abstract}

O autor desenvolve seu texto a partir de dois eixos de grande importância: a necessária construção, em ação ou processo, de uma tecnologia de avaliação com características de transdisciplinaridade e a idéia de que esta avaliação "deverá ser feita tendo como beneficiário principal o cliente/usuário do serviço/programa ou projeto".

As reflexões que faço têm como ponto de partida a declaração que inaugura o artigo: "a avaliação é uma função da gestão". Concordando com esta idéia, aponto algumas questões que têm sido trabalhadas no campo da teoria das organizações para tentar mostrar possíveis dificuldades na construção desta tão necessária prática transdisciplinar nas organizações de saúde.

Quando nosso tema é a gestão das organizações de saúde - e o artigo analisado, afinal, trata também disto - nos filiamos, de forma mais ou menos explícita, a algum paradigma teórico para pensar as organizações. Tal paradigma acaba tendo muito peso na nossa capacidade de declarar

problemas (no sentido de identificar, recortar ou antever problemas que merecerão nossa atenção) no momento mais "instrumental" de condução das mudanças organizacionais pretendidas (e a adoção da avaliação transdisciplinar é uma mudança muito profunda na cultura e forma de operar das organizações). O esforço que faço é no sentido de identificar o paradigma de organização que o autor adota e, como conseqüência, destacar aspectos que necessitam de uma discussão mais cuidadosa.

\footnotetext{
${ }_{1}^{1}$ Médico sanitarista, professor do Departamento de Medicina Preventiva e Social da Faculdade de Ciências Médicas, Universidade de Campinas. <lcecilio@correionet.com.br>
} 
Há uma primeira indicação do autor nesta direção quando afirma que "é possível iniciar o processo de avaliação com a abordagem sistêmica de administração (grifo meu) que permite analisar o processo de trabalho $e$ as relações com os resultados $e$ seguir com o estudo do impacto epidemiológico visando entender as repercursões das ações operacionalizadas para atender a população usuária ou de referência". Logo no início do artigo, a avaliação foi apontada como uma "função destinada a auxiliar o processo de decisão visando tornálo o mais racional (grifo meu) e efetivo possível". Há, ainda, uma declarada preocupação do tema da "eficiência organizacional". A partir destas indicações iniciais, pode ser dito que o autor adota como referência uma perspectiva racional tal como apontado por Lima (1994). "Nesta perspectiva (a racional) a organização é considerada como instrumento racionalmente desenhado para alcançar objetivos pré-definidos. (...) as tarefas e atividades são estruturadas segundo racionalidade técnica ou instrumental, ou seja, da maneira mais racional para que os fins sejam atingidos com uma eficiência máxima". Sob este rótulo genérico de "perspectiva racional" podem ser agrupadas várias abordagens que vão dos clássicos da administração aos comportamentalistas e decisionistas, do estruturalismo/funcionalismo weberiano/parsoniano aos "sistêmicos" $e$ "contingencialistas" e tantas outras abordagens mais contemporâneas como as propostas de gestão da qualidade total em suas inúmeras variantes. A crítica central à perspectiva racionalista é em relação ao déficit no tratamento dos atores institucionais, com seus múltiplos projetos, interesses, formas de significar a organização, controles distintos de todas as formas de recursos, inclusive de poder, conflitos, tudo enfim que nos alerta para não cairmos na tentação (ou equívoco) de pensarmos ser possível implantar uma racionalidade única na organização, por mais que ela nos pareça justa, inclusive quando ancorada no firme propósito de estar comprometida com os interesses dos usuários, como tão bem o autor se preocupa em esclarecer. Este tipo de consideração parece particularmente pertinente em relação às organizações de saúde em sua singularidade, tal qual destacado por autores como Dussault (1992) e Cecilio (2000), entre outros. Aceita a insuficiência do paradigma formal, racionalista, estratégico (Rivera, 1991), estrutural-funcionalista (Silverman, 1970) para abordar as organizações de saúde, trata-se de explorar novas abordagens das organizações, a partir de múltiplas matrizes teóricas que vão da ênfase no agir comunicativo habermasiano, à teoria da ação e à exploração das imensas possibilidades que se abrem a partir do institucionalismo (Merhy, 1998), todas com uma característica em comum: a ênfase na existência de sujeitos e seu papel ativo na construção das organizações, muito mais que em "estruturas", com sua racionalidade "macro", finalística, instrumental, capturadora de pessoas em papéis pré-estabelecidos e definidos em função dos "objetivos organizacionais".

É verdade que o autor aponta para a "possibilidade de condução da gestão da saúde com a participação de sujeitos distintos" (no contexto da municipalização) como também afirma que "é possível aproveitar ao máximo o conhecimento produzido pela prática e ao mesmo tempo envolver 
os profissionais na tomada de decisões, tornando-a mais participativa $e$ democrática". Pode ser reconhecido, nestas afirmações, um deslocamento para uma percepção mais política e comunicativa das organizações? Neste caso, estaríamos diante de uma inevitável combinação de várias "perspectivas", ou melhor, poderíamos dizer que a racionalidade mais instrumental apresentada pelo autor estaria atravessada ou interpenetrada pelo jogo de atores em situação, produtores de fatos, significados, jogadas, capazes de acumular e desacumular poder e produzir mudanças, como querem os paradigmas construídos a partir da teoria da ação ou do agir comunicativo? Pode ser e, talvez, no atual estágio de conhecimento das organizações não nos reste - diante da impossibilidade ou inexistência de uma "teoria unificada"- senão trabalhar com um ecletismo que vá dando conta de tantas questões teóricas e práticas que vamos tendo que resolver.

No entanto, permanece problemático na construção do texto o fato de a pergunta inauguradora de todo o processo - o para quê (da avaliação) - vir acompanhada de afirmações do tipo "ser necessário ter claro a decisão em jogo", saber "quem tem o poder de decidir" e "para que a decisão seja realmente efetiva". Aqui, o paradigma racionalista, estratégico e formal das organizações, implicitamente adotado pelo autor, fica mais evidente: nas organizações de saúde não há uma única decisão em jogo, nenhum ator tem o poder (ou o monopólio) para decidir e não é possível afirmar que existe uma única "efetividade", mas múltiplas efetividades, dependendo do ator que recorta a situação. A preocupação do autor de comprometer uma desejada racionalidade do processo decisório com os interesses do clientel usuário - este necessário engate da organização com "o fora"- parece não dar conta da complexidade da tarefa que é o abrir "o dentro", inclusive na construção da transdisciplinaridade. Daí que reforço a idéia de que o paradigma adotado para pensar a organização tem muito peso para orientar a formulação dos problemas que serão tratados no trajeto de implantação das idéias apresentadas no artigo.

Para finalizar, aponto um tema para futuros debates: a construção da transdisciplinaridade, por tudo o que sabemos das relações entre poder/ saber, não poderá ser adequadamente tratada sem levar em conta os importantes deslocamentos de poder em que resultará. Os vários saberes estão "colados" a atores reais, histórica e socialmente construídos e legitimados dentro, mas também aquém das organizações, como nos lembra Foucault. Não é possível "naturalizar" o encontro de saberes previsto na avaliação transdisciplinar, como se a questão "política" ou do poder
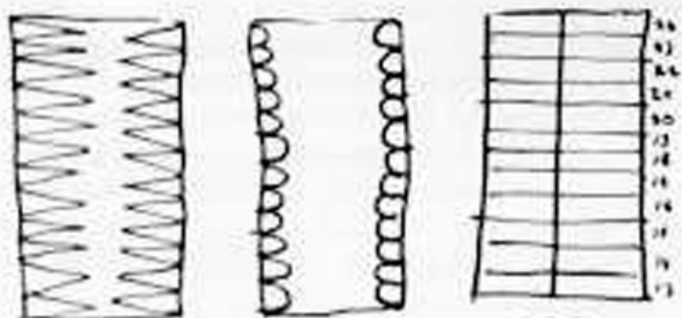
estivesse previamente resolvida. Por tudo isto, o debate posto pelo autor não poderá prescindir de uma reflexão mais cuidadosa sobre o caráter das organizações de saúde, em particular as singulares relações de poder que a caracterizam.

\section{Referências bibliográficas}

CECILIO, L.C.O. Considerações sobre alguns pares de opostos que tornam singular a gestão do hospital. Campinas: Departamento de Medicina Preventiva e Social da Universidade de Campinas, 2000. (mimeogr.)

DUSSAULT, G. A gestão dos serviços públicos de saúde. Rev. Adm. Pública, v.26, p.8-19, 1992.

LIMA, S.M.L. O processo de definição e implementação de objetivos numa organização pública no setor saúde: do conjunto sanatorial de Curicica ao hospital de clínicas básicas Raphael de Souza Paula. Rio de Janeiro, 1994. Dissertação (Mestrado) à Escola Brasileira de Administração Pública, Fundação Getúlio Vargas.

MERHY, E.E. O desafio da tutela e da autonomia: uma tensão permanente do ato cuidador.

Campinas, 1998. (mimeogr.)

RIVERA, F.J.U. Agir comunicativo e planejamento social: uma crítica ao enfoque estratégico. Rio de Janeiro: Fiocruz, 1991.

SILVERMAN, D. Teoria de las organizaciones. Buenos Aires: Nueva Visión, 1970.

PALAVRAS- CHAVE: Avaliação; tomada de decisão; organização e administração; serviços de Saúde.

KEY WORDS: Evaluation; decision making; organization and administration; health services.
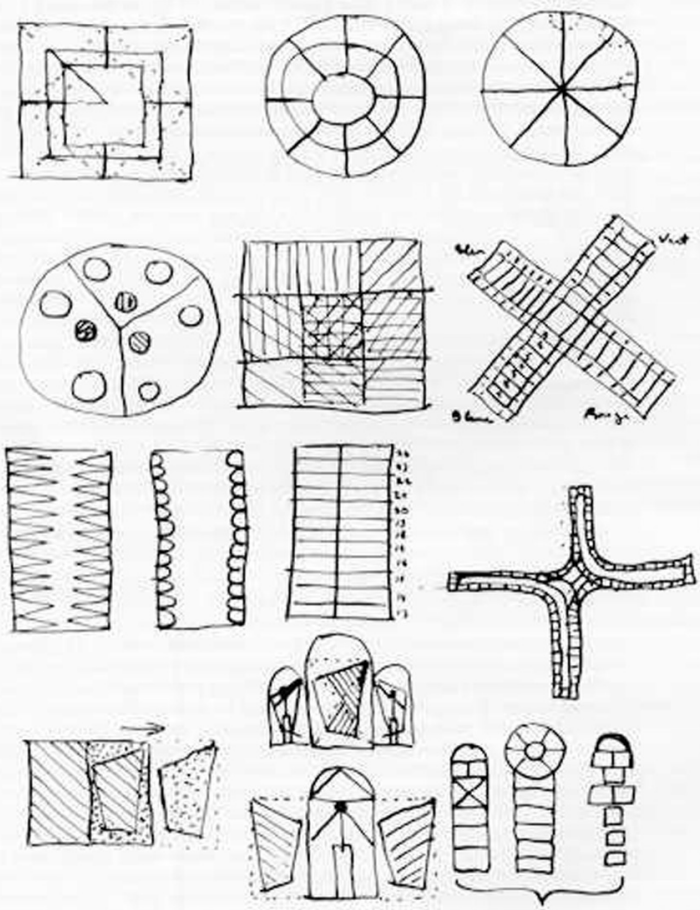

agosto, 2000 